\title{
Effects of milling on the extraction efficiency of incurred pesticides in cereals
}

\author{
Herrmann, Susan Strange; Hajeb, Parvaneh; Andersen, Gitte; Poulsen, Mette Erecius
}

Published in:

Food Additives \& Contaminants: Part A - Chemistry, Analysis, Control, Exposure \& Risk Assessment

Link to article, DOI:

$10.1080 / 19440049.2017 .1339915$

Publication date:

2017

Document Version

Peer reviewed version

Link back to DTU Orbit

Citation $(A P A)$ :

Herrmann, S. S., Hajeb, P., Andersen, G., \& Poulsen, M. E. (2017). Effects of milling on the extraction efficiency of incurred pesticides in cereals. Food Additives \& Contaminants: Part A - Chemistry, Analysis, Control, Exposure \& Risk Assessment, 34(11), 1948-1958. https://doi.org/10.1080/19440049.2017.1339915

\section{General rights}

Copyright and moral rights for the publications made accessible in the public portal are retained by the authors and/or other copyright owners and it is a condition of accessing publications that users recognise and abide by the legal requirements associated with these rights.

- Users may download and print one copy of any publication from the public portal for the purpose of private study or research.

- You may not further distribute the material or use it for any profit-making activity or commercial gain

- You may freely distribute the URL identifying the publication in the public portal 


\section{Food Additives}

\section{Contaminants}

PART A:

CHEMISTRY • ANALYSIS - CONTROL - EXPOSURE \& RISK ASSESSMENT

Toylorsfrancis

\section{Effects of milling on extraction efficiency of incurred pesticides in cereals}

\begin{tabular}{|c|c|}
\hline Journal: & Food Additives and Contaminants \\
\hline Manuscript ID & TFAC-2017-099 \\
\hline Manuscript Type: & Original Article \\
\hline Date Submitted by the Author: & 24-Feb-2017 \\
\hline Complete List of Authors: & $\begin{array}{l}\text { Herrmann, S. S.; Technical University of Denmark, National Food Institute } \\
\text { Hajeb, Parvaneh; Technical University of Denmark, National Food } \\
\text { Institute; } \\
\text { Andersen, Gitte; Technical University of Denmark, National Food Institute } \\
\text { Poulsen, Mette; National Food Institute, Technical University of Denmark, }\end{array}$ \\
\hline Methods/Techniques: & Chromatography - GC/MS, Chromatography - LC/MS \\
\hline Additives/Contaminants: & Pesticides \\
\hline Food Types: & Cereals \\
\hline Abstract: & $\begin{array}{l}\text { This study investigated the effects of particle size and milling temperature } \\
\text { on the extraction efficiencies of pesticide residues from cereal flour. } \\
\text { Samples of cereal grains were milled using a centrifugal mill with four } \\
\text { different sieves }(0.2,1.0,3.0 \text { and } 5.0 \mathrm{~mm}) \text { and a knife mill both at room } \\
\text { temperature and after freezing at }-80^{\circ} \mathrm{C} \text { overnight. The incurred pesticides }\end{array}$ \\
\hline
\end{tabular}


in the test materials were extracted by the QuEChERS method and analysed by LC-MS/MS and GC-MS/MS. The particle size distribution for the milled samples was determined using a vibratory sieve shaker. The results confirmed that smaller average particle sizes increase the extraction efficiency up to $31 \%$, with all other factors held constant. The cereals milled at room temperature produced lower pesticide recoveries compared to cereals milled when still frozen, especially for heat-sensitive pesticides. Furthermore, milling frozen grains was easier and resulted in more homogeneous samples with smaller relative particle sizes (RPS). 


\section{Effects of milling on extraction efficiency of incurred pesticides in cereals}

Susan S. Herrmann; Parvaneh Hajeb*; Gitte Andersen, and Mette E. Poulsen

National Food Institute, Technical University of Denmark, Mørkhøj Bygade 19, DK-2860

Søborg, Denmark

${ }^{*}$ Corresponding author. Tel +4535887000

Email address: parha@food.dtu.dk (P. Hajeb) 


\begin{abstract}
This study investigated the effects of particle size and milling temperature on the extraction efficiencies of pesticide residues from cereal flour. Samples of cereal grains were milled using a centrifugal mill with four different sieves $(0.2,1.0,3.0$ and $5.0 \mathrm{~mm})$ and a knife mill both at room temperature and after freezing at $-80{ }^{\circ} \mathrm{C}$ overnight. The incurred pesticides in the test materials were extracted by the QuEChERS method and analysed by LC-MS/MS and GC-MS/MS. The particle size distribution for the milled samples was determined using a vibratory sieve shaker. The results confirmed that smaller average particle sizes increase the extraction efficiency up to $31 \%$, with all other factors held constant. The cereals milled at room temperature produced lower pesticide recoveries compared to cereals milled when still frozen, especially for heat-sensitive pesticides. Furthermore, milling frozen grains was easier and resulted in more homogeneous samples with smaller relative particle sizes (RPS).
\end{abstract}

KEYWORDS: Pesticides, QuEChERS, extraction efficiency, cereals, milling, particle size 


\section{Introduction}

Since ancient times, cereals have been a large component of the human diet. Because cereals are one of the foods most produced and consumed in the world, their safety is important. Cereals frequently receive intense applications of pesticides over their whole growing and post-harvesting periods. Therefore, food-safety issues introduced by food contamination from pesticide residues are becoming increasingly important. To ensure a high level of food safety, several techniques for pesticides residue analysis have been developed. Among the different analytical approaches developed so far, the QuEhERS (Quick, Easy, Cheap, Effective, Rugged, and Safe) method has become particularly important in this field due to its inherent advantages (Anastassiades et al. 2003; Lehotay et al. 2005; AOAC 2007; Sack et al. 2011). Several factors may have an impact on pesticide extractability from cereals, such as the physicochemical properties of the pesticides, the accumulation of pesticides in the inner or cuticle parts of the grains, the time of pesticide application, and the crop type (Hepperle et al. 2015). The incurred pesticide residues are not always easy to extract because they might be enclosed in cells, starch, or fat particles or may undergo strong interactions with the matrix. Factors such as the extraction temperature and time, the choice of solvent, the sample to solvent ratio, and the sample particle size can greatly influence the extraction efficiency of certain pesticides. It is common to study the role of these factors and optimise them when developing extraction methods, with the exception of the role of the sample particle size. However, the effects that homogenisation/grinding to different extents or by different procedures have on the extractability of analytes are not commonly studied or published. In Anastassiades (Anastassiades et al. 2003), the authors describe the developmental work behind the QuEChERS method and state that laboratories rarely evaluate the quality of the sample comminution step in their quality control procedures and that the procedures used vary significantly from laboratory to laboratory. Common methods 
include homogenising/grinding or milling the sample using a standard procedure or to the smallest particles possible with the equipment available. This strategy is based on the assumption that a smaller particle size of the sample results in more efficient extraction because the surface area that is accessible to the solvent increases with decreasing particle size.

To our knowledge, literature highlighting the effect of particle size on the extraction efficiency of pesticides in flour is very scarce. Recently, Hepperle et al. (Hepperle et al. 2015) studied milled and re-milled rice and wheat. However, except for chlorpyrifos in a wheat sample, they did not find higher extraction yields for other pesticides as a result of a higher comminution grade. Some data are available for other matrices. A relationship between smaller particle sizes and higher extraction efficiencies has been reported for the extraction of organochlorine pesticides from ginseng root (Quan et al. 2004); although, it has also been reported that the extraction efficiency of organochlorine pesticides from homogenised sunflower seeds is lower with a particle size of $0.2 \mathrm{~mm}$ than with a particle size of $0.8 \mathrm{~mm}$ because the sample with the low particle size becomes compact (R. Prados-Rosales, J. Luque García 2003). Thus, there may be a lower limit for which the positive relationship between the particles size and the extraction efficiency no longer exists. In other fields of research, studies have also confirmed the expected higher extraction efficiency with lower particle size, e.g., for the extraction of paprika by supercritical fluid extraction (Nagy \& Simándi 2008) and for the extraction of natural constituents (berberine and aristolochic acids) from medicinal plants by pressurised liquid extraction (PLE) (Ong et al. 2000). Particle size was thought to be less critical for the extraction efficiency when using PLE because of the high pressure applied, but the state of the sample is also of importance when using this technique.

Therefore, thorough homogenisation to obtain small and homogeneous particle sizes is expected to be of great importance in the analysis of pesticide residue in cereals and all other 
fields of quantitative analysis. Nevertheless, sample particle size is not evaluated when laboratories participate in proficiency tests regarding pesticide residue analysis. The proficiency test materials are homogenised/grinded/milled by the provider of the test. For a European reference laboratory, it is a priority to provide knowledge-based advice to optimise and to harmonise the analytical performances of the European laboratories involved in pesticide residue control. The aim of the present study was therefore to study whether there is a relationship between the particle sizes of wheat, rye, oat and barley flour and the efficiency with which the incurred pesticides are extracted. Additionally, the heat produced during milling may affect the heat sensitive pesticides. Therefore, we investigated whether freezing the cereal grains before milling could prevent pesticide losses.

\section{Experimental}

\section{Chemicals}

The pesticide standards (all with a purity > 96\%) were purchased from Dr. Ehrenstorfer (Augsburg, Germany). Acetonitrile (HPLC Grade S) was purchased from Rathburn Chemicals (Walkerburn, UK) and acetic acid and ammonium acetate were from Merck (Darmstadt, Germany). The magnesium sulphate was purchased from J.T. Baker, Aventor Performance Materials B.V (Center Valley, PA 18034, USA), sodium chloride from Merck \& Co. (Whitehouse Station, NJ, USA), sodium citrate dehydrate and sodium citrate sesquihydrate from Sigma Aldrich Chemie GmbH (Taufkirchen, Germany), and the clean/up sorbents PSA from Agilent Technologies (Santa Clara, CA 95051, USA) and C18 from International Sorbent Technology Ltd. (Gengoed Mid Glam, UK). The pesticide standard stock solutions of $1 \mathrm{mg} / \mathrm{ml}$ were prepared in toluene and stored at $-18{ }^{\circ} \mathrm{C}$ in ampoules with an argon atmosphere. A standard mixture of $10 \mu \mathrm{g} / \mathrm{ml}$ in acetonitrile was prepared from these 
stock solutions. Working solutions were prepared by diluting this standard mixture and finally matching them 1:1 with the extracts of blank flours (not containing pesticide residues) to obtain a concentration range of $0.0003-0.333 \mu \mathrm{g} / \mathrm{ml}$. The extracts used for the matrix matching were obtained by the extraction and clean-up procedure described in Section 2.2, which was used as our standard procedure.

\section{Sample and sample preparation}

The samples used in this study were cereal grains grown and sprayed in the field produced in connection with the production of proficiency test material for the four EUPTs: EU-PT-C2 (wheat), C3 (oat), C4 (rye) and C6 (barley). The levels of the incurred pesticides in the test material, which are determined with our in-house method involving milling with a $1 \mathrm{~mm}$ sieve size, extraction by the in-house QuEChERS method (see section 0 ) and analysis by LCMS/MS and GC-MS/MS, are presented in Table 1.

Samples of the cereal grains along with the corresponding blanks were milled at room temperature using a centrifugal mill (Retsch, Haan, Germany) with four different sieves: 0.2 , 1.0, 3.0 and $5.0 \mathrm{~mm}$ and a coffee grinder (Bodum, Switzerland). To study the effects of temperature, the oat and rye samples were also milled after freezing at $-80{ }^{\circ} \mathrm{C}$ overnight. Milling of the test materials was performed in duplicate, and the untreated samples (blank) were treated individually. For each milling, $200 \mathrm{~g}$ of sample was employed.

The water content of the grain was determined by drying $5 \mathrm{~g}$ (in duplicate) under a vacuum at $70^{\circ} \mathrm{C}$ for at least 16 hours or until the gravimetric determination stabilised.

\section{Particle size distribution analysis}


The particle size distribution from the milled samples of wheat, oat, rye and barley was determined using a vibratory sieve shaker (Retsch AS 200, Haan, Germany). The sieving parameters (sample size, sieve time and amplitude) were optimised using different sample sizes (50 and $100 \mathrm{~g})$, amplitudes $(2-3 \mathrm{~mm}$ ) and sieving times (10-20 $\mathrm{min})$. The optimal sieving conditions that produced the most efficient separation of the flour particles were using $50 \mathrm{~g}$ of flour samples with 20 min of sieving time at amplitude of $2.5 \mathrm{~mm}$. The flour samples were separated into fractions according to the sieve mesh sizes ranging from $50 \mu \mathrm{m}$ to 4.8 $\mathrm{mm}$. Sieving of the test materials was performed in duplicate.

The relative particle size (RPS) of each milled sample was calculated using the following formula:

$$
R P S=\sum_{i=1}^{n}(A S * S A)
$$

RPS: relative particle size

AS: average sieve mesh size (calculated as the average between sieve $n$ and sieve $n-1$ )

SA: sample amount in sieve $\mathrm{n}(\mathrm{g})$

The size distributions and particle shapes of the selected samples were also observed under a Leica (DMR) light microscope. The microscope was attached to a camera (Leica DFC295) to capture the digital images, and image analysis software (Image-Pro Plus 7.0; Media Cybernetics, Bethesda, MD, USA) was used for the size measurements. 


\section{Pesticides extraction and clean-up procedure}

The samples were extracted using our in-house standard procedure for cereals (in accordance with QuEChERS EN 15662) (Herrmann \& Poulsen 2015). Briefly, $5.0 \mathrm{~g}$ of milled cereal was added to $10 \mathrm{ml}$ of cold water and immediately extracted with $10 \mathrm{ml}$ of acetonitrile by shaking the tube for $1 \mathrm{~min}$ by hand. To aid the extraction, a ceramic homogeniser was included. Next, $4.0 \mathrm{~g}$ of magnesium sulphate, $1.0 \mathrm{~g}$ of sodium chloride, $1.0 \mathrm{~g}$ of sodium citrate dihydrate and $0.5 \mathrm{~g}$ of sodium citrate sesquihydrate were added. After $1 \mathrm{~min}$ of shaking by hand followed by centrifugation for $10 \mathrm{~min}$ at $4300 \mathrm{G}, 8 \mathrm{ml}$ of the supernatant was transferred to a clean tube and stored at $-80{ }^{\circ} \mathrm{C}$ for minimum $1 \mathrm{~h}$. The extracts were then thawed, and when they were still very cold, they were centrifuged at $4300 \mathrm{G}$ for $5 \mathrm{~min}$. Thereafter, $6 \mathrm{ml}$ of the cold supernatant was mixed with $150 \mathrm{mg}$ of PSA and $900 \mathrm{mg}$ of magnesium sulphate. After shaking for $30 \mathrm{~s}$ and centrifuging for $5 \mathrm{~min}$ at $3400 \mathrm{G}$, the extract was added to $40 \mu \mathrm{l}$ of $5 \%$ formic acid solution and analysed by GC-MS/MS and LC-MS/MS.

\section{Chromatographic separation and detection}

GC-MS/MS analysis was performed on a Quattro Micro Tandem GC-MS/MS (Waters, USA). The system consisted of a PAL-GC Auto sampler, an Agilent GC 6890N and a Quattro Micro Tandem mass spectrometer. The GC was equipped with a Gerstel PTV injector for large volumes, and $4 \mu \mathrm{l}$ of sample was injected. The injector program started with an initial temperature of $30{ }^{\circ} \mathrm{C}$ for $0.8 \mathrm{~min}$ followed by a ramp of $480{ }^{\circ} \mathrm{C} / \mathrm{min}$ to $290{ }^{\circ} \mathrm{C}$. The temperature was held for $2 \mathrm{~min}$ and was then raised at a rate of $720^{\circ} \mathrm{C} / \mathrm{min}$ to $330^{\circ} \mathrm{C}$ to clean the injector. The GC oven program started with an initial temperature of $60^{\circ} \mathrm{C}$ held for 3 min, followed by a ramp of $30^{\circ} \mathrm{C} / \mathrm{min}$ to $180{ }^{\circ} \mathrm{C}$. This temperature was held for $0.8 \mathrm{~min}$, before being increase at a rate of $5^{\circ} \mathrm{C} / \mathrm{min}$ to $280^{\circ} \mathrm{C}$ and subsequently held for $3 \mathrm{~min}$. To 
clean the column, the temperature was raised at a rate of $40^{\circ} \mathrm{C} / \mathrm{min}$ to $300^{\circ} \mathrm{C}$ for $10 \mathrm{~min}$ and $120^{\circ} \mathrm{C} / \mathrm{min}$ to $310^{\circ} \mathrm{C}$ for $1 \mathrm{~min}$. The chromatographic separation was performed on a RESTEK, Rxiß-5 ms, $30 \mathrm{~m}, 0.25 \mathrm{~mm}$ ID, $0.25 \mu \mathrm{m}$ df column with a constant flow of 1.3 $\mathrm{ml} / \mathrm{min}$ of helium as the carrier gas. The temperatures of the transfer line and ion source were set at $250{ }^{\circ} \mathrm{C}$ and $180^{\circ} \mathrm{C}$, respectively. The mass spectrometer was operated in electronic ionisation mode (EI, $70 \mathrm{eV}$ ). The analysis in scan mode was employed to obtain TIC chromatograms for the determination of the intensities of the matrix peaks. MRM was used to perform the mass spectrometric quantification of the pesticides. The employed MRM transitions, retention times and collision energies are listed in Table 2.

The LC-MS/MS analysis was performed on an HP1100 liquid chromatograph (Agilent Technologies, Palo Alto, CA, USA) connected to a Micromass Quattro Ultima Triple Quadrupole Instrument. The injection volume was $10 \mu$ l. The chromatographic separation was performed on a Genesis C18 column, $100 \mathrm{~mm} \times 3 \mathrm{~mm}, 4 \mathrm{~m}$ pore size, (Gracevydac, Hengoed, UK). Before the separation column was a Phenomenex SecurityGuard column, C18 ODS, $4 \mathrm{~mm} \times 2 \mathrm{~mm}$ (Cheshire, UK). Solvent A was an ammonium acetate/acetic acid solution containing $20 \mathrm{mM}$ of each. Solvent B was $95 \%$ methanol and $20 \mathrm{mM}$ each of ammonium acetate and acetic acid. The total flow rate of eluents $A$ and $B$ was $0.3 \mathrm{ml} / \mathrm{min}$. The initial gradient was $100 \% \mathrm{~A}$, decreasing to $50 \% \mathrm{~A}$ after $2 \mathrm{~min}$ and $0 \% \mathrm{~A}$ after $20 \mathrm{~min}$. Solvent A was held at $0 \%$ until $24 \mathrm{~min}$. The total run time was $30 \mathrm{~min}$. The retention times are shown in Table 2. Ionisation was performed using electrospraying in positive ion mode (ESI+) and the mass spectrometer in MRM mode. The capillary voltage was set to $1.0 \mathrm{kV}$. The source temperature was $120^{\circ} \mathrm{C}$, and the desolvation temperature was $350^{\circ} \mathrm{C}$. Nitrogen was used as the desolvation gas (flow $550 \mathrm{l} / \mathrm{h}$ ) and cone gas (flow $50 \mathrm{l} / \mathrm{h}$ ), and argon was used as the collision gas at a pressure of $1.7 \times 10-3$ mbar. The MRM transitions, retention times and collision energies employed for the LC-MS/MS analysis are listed in Table 3. 
The quantification was based on the bracketing calibration curves of five matrix matched standard solutions, covering the relevant concentration range. Exact matrix matching was employed, i.e., the pesticide content of the oats test material was quantified using the calibration solutions matrix-matched with the oats blank material, and for rye, using the calibration solution matrix-matched with the rye blank material.

\section{Results and discussion}

To elucidate the often-overlooked effect of the particle size on the extraction efficiency, we have studied the possible relation between the decreasing particle size and the efficiency of 33 incurred pesticide residues extracted from cereal flours, i.e., wheat, oat, rye and barley.

\section{Particle size distribution of flour}

To find justification for any variations in the pesticide extraction efficiencies from grain in relation to the particle size, we investigated the particle size distributions at each of the milling sizes. Milling with sieve sizes of $1.0 \mathrm{~mm}$ and $3.0 \mathrm{~mm}$ gave more or less an even particle size distribution. However, we observed that milling with a sieve size of $0.2 \mathrm{~mm}$ apparently results in a large proportion of particles larger than $0.2 \mathrm{~mm}$. For instance, in oats and rye milled with a sieve size of $0.2 \mathrm{~mm}$, more than $65 \%$ of the particles were larger than $0.2 \mathrm{~mm}$ (Figure 1b \& 1c). Milling at a sieve size of $5.0 \mathrm{~mm}$ and with the knife mill resulted in a very in-homogeneous flour, containing both small $(<0.05 \mathrm{~mm})$ and large particles $(>0.7 \mathrm{~mm})$ (Figure 1a-1d). The average particle size of all the cereals showed that the knife mill produces greater amounts of large particles (more than $50 \%$ of the particles were $>0.7 \mathrm{~mm}$ ). The size distribution showed that grinding the frozen samples resulted in more homogeneous 
flour samples with greater proportions of smaller particles (Figure 1e \& 1f). Cryogenic milling resulted in greater amounts of smaller particles, especially at a mill size of 0.2 . However, cryogenic milling did not show such effects on particle size of the flours milled with a sieve size of $5.0 \mathrm{~mm}$ and the knife mill.

As expected, the relative particle size (RPS) was smaller for grains milled with a smaller sieve size. However, the RPS of oat flour at each sieve size (except for the sieve size of 3.0 $\mathrm{mm}$ ) was the largest among the four grains studied; whereas, wheat flour showed the smallest RPS among the four flours. These differences may be due to differences in the hardness, moisture and fat content of the grains. Cryogenic milling resulted in a smaller RPS for each sieve size, except for the sieve size of $0.2 \mathrm{~mm}$ and the knife mill, which did not exhibit any considerable differences. The knife mill resulted in the largest RPS of the tested milling conditions.

Inspection of the shape of the flour particles under a microscope revealed that the milled cereals have very inhomogeneous particles from round to long shapes (Figure 2). From the dimensions of the particles, it can be concluded that the particles that are smaller in just one dimension than the mesh size of the sieve can pass through it. Consequently, some of the particles from the flour milled with a specific mesh size of the sieve are found to be larger than the sieve size when sieved using a vibratory sieve shaker.

\section{Extraction efficiency of different particle sizes.}

The recoveries of the incurred pesticides from the flours milled with the different sieve sizes were calculated for each type of grain and compared with the recoveries obtained for the corresponding samples milled with a sieve size of $1.0 \mathrm{~mm}$. A comparison of the average recoveries, with all of the pesticides summed, showed that the extraction efficiencies 
improved by up to $31 \%$ when the sieve mesh size was reduced from $5.0 \mathrm{~mm}$ to $0.2 \mathrm{~mm}$ (Figure 3). The average recoveries for all cereals were $116,100,97,85$, and $80 \%$ when milled with a sieve size of $0.2,1.0,3.0,5.0$, and the knife mill, respectively. The average recoveries, with all of the pesticides summed, ranged between $92-106 \%$ for wheat, $76-120 \%$ for oat, $74-105 \%$ for rye, and $87-132 \%$ for barley when milled with sieve sizes of $0.2-5.0 \mathrm{~mm}$.

For all four types of cereals, a similar pattern was observed; the highest extraction efficiencies were achieved when the samples where milled with a sieve size of $0.2 \mathrm{~mm}$, except for some of the detected pesticides in wheat (Figure 4). The relationship was most clearly demonstrated by the results obtained for oats and rye (Figure 4c and 4d, respectively). The extraction efficiency for grain milled using the knife mill varied for the different types of cereals and pesticides (Figure 4c-d). Oats milled with the knife mill showed the lowest extraction efficiency for all of the pesticides, which is in good agreement with the fact that the knife mill provided the largest RPS. Rye milled with the knife mill showed the highest extraction efficiencies for azoxystrobin and carbendazim. It also exhibited slightly higher extraction efficiencies than the sieve size of $5.0 \mathrm{~mm}$ for most of the pesticides. This finding could be due to the very inhomogeneous flour produced by the knife mill, which contained both very small and very large particles. As mentioned in the previous section, the amount of particles with smaller sizes $(0.2 \mathrm{~mm})$ was higher compared to milling at $5.0 \mathrm{~mm}$. In this study, all of the pesticides had been applied to the field 20-30 days before harvesting, except for malathion and chlorpyrifos-methyl, which were applied 10 days before harvesting. Therefore, it is expected that most of the malathion and chlorpyrifos-methyl residues remained in the outer parts of the grain.

It is observed that the extraction efficiency of pesticides was less affected by the particle size for wheat than for the other grains. This could be related to the fact that in oats and barley, the husk is fused together with the bran, while wheat and rye are naked cereals $(P$. Koehler 
2013). When the grain matures (dries) in the field, the water evaporates from the oats/barley hull; whereas for rye/wheat, it evaporates from the bran/surface of the grain. It would therefore be expected that the residues found in wheat are, to a large extent, associated with the bran of the grain; whereas, residues in the oats remain in the grain. It is also assumed that pesticide residues are more evenly distributed in the oats/barley grains because if the residues have become more concentrated as a result of the drying process, it has occurred on the surface of the hull, which is removed before milling and analysis. However, the results obtained for rye in the current study did not fully explain this theory, and there might be other factors affecting the distribution of pesticides in rye.

During milling, and especially when milling with a sieve size of $0.2 \mathrm{~mm}$ and using the knife mill, heat was produced. This heat could result in the evaporation of water from the sample material. The loss of water could introduce an error in the study because the dry weight of the different millings would vary and in addition to a variation in the actual sample size extracted. Thus, an increase in the extraction efficiency for the samples milled to $0.2 \mathrm{~mm}$ could be the result of water evaporation and not from an increase in the accessibility of the finely milled samples. Therefore, the water content of the different flour samples was determined gravimetrically. A reduction in the water content was only observed for the samples milled to a particle size of $0.2 \mathrm{~mm}$, i.e., $1.0-5.3 \%$, and the greatest reduction was demonstrated for rye and barley. However, the correction of the quantitative results for the loss of water had little effect on the determined pesticide content and could therefore not explain the higher extraction efficiency observed when the grain was milled to a particle size of $0.2 \mathrm{~mm}$.

\section{Cryogenic milling}


As explained above, the heat produced during milling was a result of the friction between the blades of the grinder. Thus, the lower recoveries of heat-sensitive pesticides could result during milling. Some of the pesticides, such as pyrethroids, which are represented by deltamethrin and lambda-cyhalothrin in the present study, have been reported as heat sensitive pesticides (Senneca et al. 2007). To study the effect of heat on the recoveries of the incurred pesticides, oat and rye grains were stored at $-80^{\circ} \mathrm{C}$ overnight prior to milling. Figure $4 \mathrm{e}$ and $4 \mathrm{f}$ show that the recoveries of pesticides from frozen oats and rye are generally comparable with the recoveries found for samples milled at room temperature. For most of the pesticides, especially in the oat grains, a slightly higher recovery was observed for the samples milled at low temperatures. Thus, the present study showed that milling at a low temperature may improve the recoveries of some pesticides, but overall the results produced are similar. Although, milling at a low temperature made the milling process itself easier, especially for oats, by reducing the tendency of the flour to clot.

Carbendazim, chlorpyriphos-methyl, deltamethrin, lambda-cyhalothrin, malathion, and pirimiphos-methyl have been reported as thermally unstable compounds that undergo evaporation, degradation or polymerisation during heating (B.S. Joia, G.R.B. Webster 1985; Robert Mestres 1992; Yoshihiro HORI, Takao CHONAN 1992; Sharma et al. 2005; Uygun et al. 2005). In fact, for some of the mentioned compounds (carbendazim, lambda-cyhalothrin, and pirimiphos-methyl), slightly improved recoveries were observed in the present study when milling was performed using frozen grains instead of grains at room temperature. Performing the milling on frozen grains increased the extraction recoveries not only of heat sensitive pesticides but also strobilurin analogue (azoxystrobin and kresoxim-methyl) and organophosphorus pesticides (Chlorpyrifos-methyl, malathion and pirimiphos-methyl), especially at larger mill sizes. Thus, the slightly higher recoveries indicated for the samples milled at low temperature in the present study may not be related to less heat-induced 
pesticide degradation, but to a larger proportion of small particles in the flour milled at low temperatures compared to flour milled at room temperature, as described above (section 3.1 and Figure 1e \& 1f).

Grinding at a larger sieve size $(5.0 \mathrm{~mm})$ and with a knife mill resulted in very inhomogeneous flour with the largest relative particle size (RPS). Cryogenic milling resulted in more homogeneous flour samples with greater proportions of smaller particle sizes and smaller RPS. The present study supports the assumption that small particle sizes increase pesticide extraction efficiencies with all other factors remain equal. The observed effect of the particle size was demonstrated for the incurred pesticides and not the spiked pesticides. A comparison of the average recoveries, when all of the pesticides are summed, showed that the extraction efficiencies improved by up to $31 \%$ when the sieve mesh size was reduced from $5.0 \mathrm{~mm}$ to $0.2 \mathrm{~mm}$. The extraction efficiency of the pesticides in wheat was influenced less by particle size than in the other grains. The extraction efficiency for grains milled using the knife mill varied for the different types of cereals and pesticides. In general, cereals milled at room temperature produced lower pesticide recoveries compared to low-temperature milling, especially for the heat-sensitive pesticides. Furthermore, when grinding at low temperatures, the milling process itself was easier, especially for oats, because of a reduction in the tendency of the flour to clot.

\section{References}

Anastassiades M, Lehotay SJ, Stajnbaher D, Schenck F. 2003. Fast and easy multiresidue method employing acetonitrile extraction/partitioning and "dispersive solid-phase extraction" for the determination of pesticide residues in produce. J AOAC Int. 86:412-431.

AOAC. 2007. Official Method 2007.01: Pesticide Residues in Foods by Acetonitrile Extraction and Partitioning with Magnesium Sulfate. J AOAC Int [Internet]. 90:17 - 26. Available from: http://lib3.dss.go.th/fulltext/E_content/1060-3271/2007v90n2.pdf 
B.S. Joia, G.R.B. Webster SRL. 1985. Cypermethrin and fenvalerate residues in stored wheat and milled fractions. J Agric Food Chem. 33:618-622.

Hepperle J, Dörk D, Barth A, Taşdelen B, Anastassiades M. 2015. Studies to improve the extraction yields of incurred pesticide residues from crops using the QuEChERS method. J AOAC Int. 98:450-463.

Herrmann SS, Poulsen ME. 2015. Clean-up of cereal extracts for gas chromatographytandem quadrupole mass spectrometry pesticide residues analysis using primary secondary amine and C18. J Chromatogr A. 1423:47-53.

Lehotay SJ, Maštovská K, Lightfield AR. 2005. Use of buffering and other means to improve results of problematic pesticides in a fast and easy method for residue analysis of fruits and vegetables. J AOAC Int. 88:615-629.

Nagy B, Simándi B. 2008. Effects of particle size distribution, moisture content, and initial oil content on the supercritical fluid extraction of paprika. J Supercrit Fluids [Internet]. 46:293298. Available from: http://www.sciencedirect.com/science/article/pii/S0896844608001332

Ong ES, Woo SO, Yong YL. 2000. Pressurized liquid extraction of berberine and aristolochic acids in medicinal plants. J Chromatogr A. 904:57-64.

P. Koehler HW. 2013. Chemistry of Cereal Grains. In: M. Gobbetti MG, editor. Handb Sourdough Biotechnol. New York: Springer Science+Business Media; p. 11-15.

Quan L, Li S, Tian S, Xu H, Lin A, Gu L. 2004. Determination of Organochlorine Pesticides Residue in Ginseng Root by Orthogonal Array Design Soxhlet Extraction and Gas Chromatography. Chromatographia.:89-93.

R. Prados-Rosales, J. Luque García ML de C. 2003. Rapid analytical method for the determination of pesticide residues in sunflower seeds based on focused microwave-assisted Soxhlet extraction prior to gas chromatography - tandem mass spectrometry. J Chromatogr A. 993:121-129.

Robert Mestres GM. 1992. Deltamethrin: uses and environmental safety. Rev Environ Contam Toxicol. 124:1-18.

Sack C, Smoker M, Chamkasem N, Thompson R, Satterfield G, Masse C, Mercer G, Neuhaus B, Cassias I, Chang E, et al. 2011. Collaborative validation of the QuEChERS procedure for the determination of pesticides in food by LC-MS/MS. J Agric Food Chem. 59:6383-6411.

Senneca O, Scherillo F, Nunziata A. 2007. Thermal degradation of pesticides under oxidative conditions. J Anal Appl Pyrolysis. 80:61-76.

Sharma J, Satya S, Kumar V, Tewary DK. 2005. Dissipation of pesticides during breadmaking. Chem Heal Saf. 12:17-22. 
Uygun U, Koksel H, Atli A. 2005. Residue levels of malathion and its metabolites and fenitrothion in post-harvest treated wheat during storage, milling and baking. Food Chem. 92:643-647.

Yoshihiro HORI, Takao CHONAN MS and MO. 1992. Residues of organophosphorus pesticides in wheat after milling and cooking. J Food Hyg Soc Japan. 33:144-149. 


\section{Figure captions}

Figure 1. Particle size ( $\mathrm{mm})$ distribution of a) wheat, b) barley, c) oats, d) rye milled at room temperature and e) oat, f) rye milled frozen with sieve size at $0.2,1.0,3.0,5.0 \mathrm{~mm}$ and the knife mill.

Figure 2. A microscopic image of the different particle sizes from oats milled at a $2.0 \mathrm{~mm}$ sieve size.

Figure 3: The average recovery for all pesticide residues in all four cereals (wheat, oats, rye and barley) milled at room temperature with sieve sizes of $0.2,1.0,3.0$, and $5.0 \mathrm{~mm}$.

Figure 4: The recovery ((detected level/reference value $\left.)^{\star} 100\right)$ of different pesticides in a) wheat, b) barley, c) oats, and d) rye milled at room temperature and e) oats and f) rye milled at a low temperature with sieve sizes of $0.2,1.0,3.0$, and $5.0 \mathrm{~mm}$ and the knife mill (K.M.). 


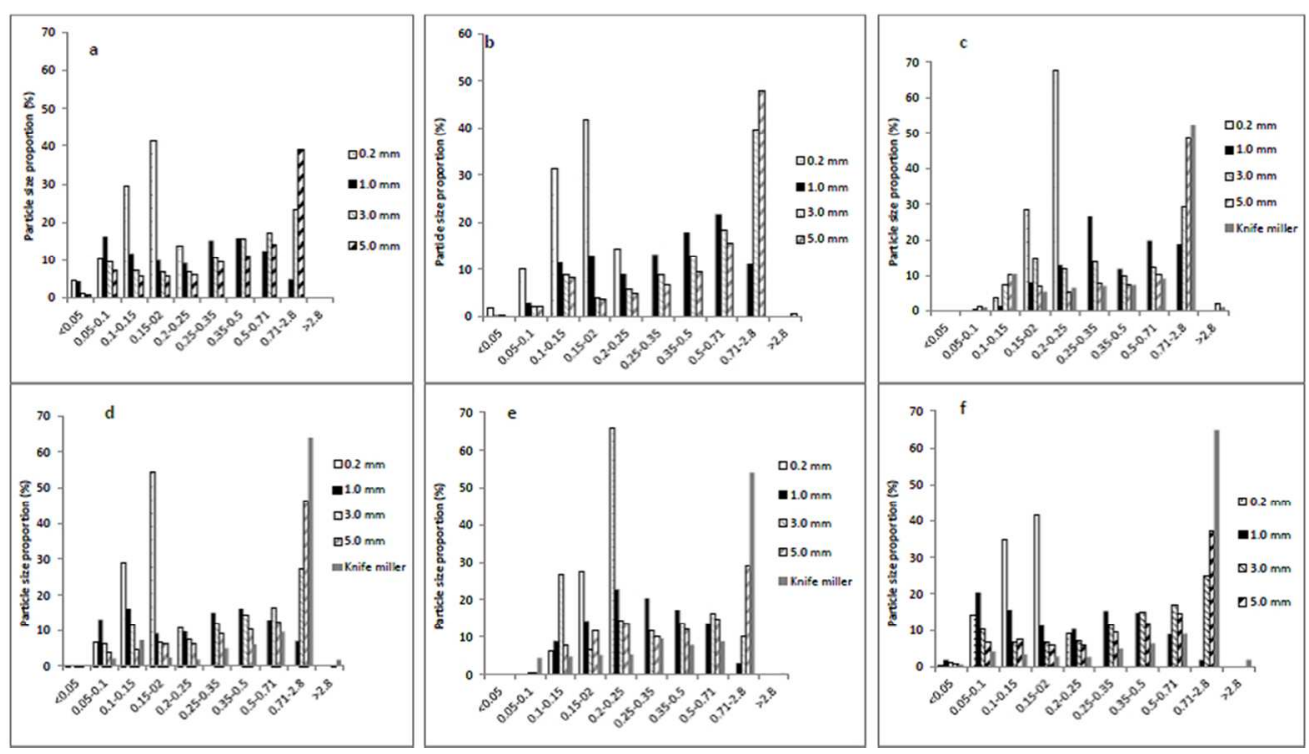

Figure 1. Particle size $(\mathrm{mm})$ distribution of a) wheat, b) barley, c) oats, d) rye milled at room temperature and e) oat, f) rye milled frozen with sieve size at 0.2, 1.0, 3.0, $5.0 \mathrm{~mm}$ and the knife mill.

$237 \times 134 \mathrm{~mm}(96 \times 96 \mathrm{DPI})$ 
Figure 2. A microscopic image of the different particle sizes from oats milled at a $2.0 \mathrm{~mm}$ sieve size.

$156 \times 58 \mathrm{~mm}(96 \times 96 \mathrm{DPI})$ 
Figure 3: The average recovery for all pesticide residues in all four cereals (wheat, oats, rye and barley) milled at room temperature with sieve sizes of $0.2,1.0,3.0$, and $5.0 \mathrm{~mm}$.

\section{$99 \times 59 \mathrm{~mm}(96 \times 96 \mathrm{DPI})$}




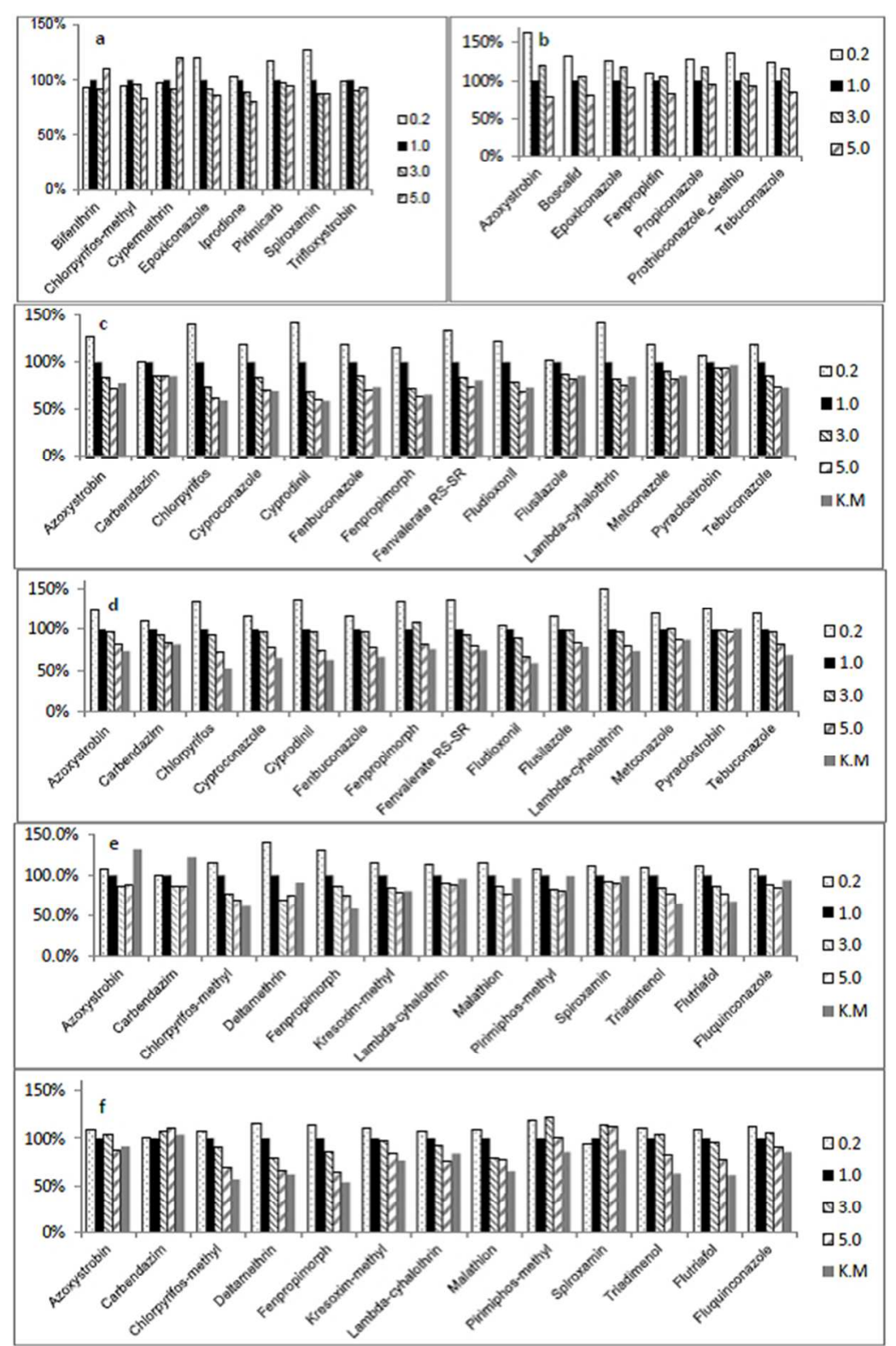

Figure 4: The recovery ((detected level/reference value)*100) of different pesticides in a) wheat, b) barley, c) oats, and d) rye milled at room temperature and e) oats and f) rye milled at a low temperature with sieve sizes of $0.2,1.0,3.0$, and $5.0 \mathrm{~mm}$ and the knife mill (K.M.).

\section{$149 \times 226 \mathrm{~mm}(96 \times 96 \mathrm{DPI})$}


Table 1. The levels of incurred pesticides $(\mathrm{mg} / \mathrm{kg})$ in grains milled at room temperature with a sieve size of $1.0 \mathrm{~mm}$.

\begin{tabular}{|c|c|c|c|c|}
\hline \multirow[b]{2}{*}{ Compounds } & \multicolumn{4}{|c|}{ Reference value $(\mu \mathrm{g} / \mathrm{g})$} \\
\hline & Oats & Rye & Wheat & Barley \\
\hline Azoxystrobin & 0.184 & 0.310 & - & 0.149 \\
\hline Bifenthrin & - & - & 0.106 & - \\
\hline Boscalid & - & - & - & 0.819 \\
\hline Carbendazim & 0.440 & 1.121 & - & - \\
\hline Chlorpyrifos & 1.054 & - & - & - \\
\hline Chlorpyrifos-methyl & - & 0.094 & 0.151 & - \\
\hline Cypermethrin & - & - & 0.1325 & - \\
\hline Cyproconazole & 1.013 & - & - & - \\
\hline Cyprodinil & 0.075 & - & - & - \\
\hline Deltamethrin & - & 0.057 & - & - \\
\hline Epoxiconazole & - & - & 0.181 & 0.569 \\
\hline Fenbuconazole & 0.554 & - & - & - \\
\hline Fenpropidin & - & - & - & 1.195 \\
\hline Fenpropimorph & 0.162 & 2.063 & - & - \\
\hline Fenvalerate & 0.099 & - & - & - \\
\hline Fludioxonil & 0.108 & - & - & - \\
\hline Fluquinconazole & - & 0.629 & - & - \\
\hline Flusilazole & 0.814 & - & - & - \\
\hline Flutriafol & - & 2.812 & - & - \\
\hline Iprodione & - & - & 0.394 & - \\
\hline Kresoxim-methyl & - & 0.425 & - & - \\
\hline Lambda-cyhalothrin & 0.033 & 0.036 & - & - \\
\hline Malathion & - & 0.094 & - & - \\
\hline Metconazole & 0.564 & - & - & - \\
\hline Pirimicarb & - & - & 0.032 & - \\
\hline Pirimiphos-methyl & - & 0.048 & - & - \\
\hline Propiconazole & - & - & - & 0.2175 \\
\hline $\begin{array}{l}\text { Prothioconazole_des } \\
\text { thio }\end{array}$ & - & - & - & 0.080 \\
\hline Pyraclostrobin & 0.816 & - & - & 0.001 \\
\hline Spiroxamin & - & 1.15 & 0.059 & -8 \\
\hline Tebuconazole & 1.787 & - & - & 0.513 \\
\hline Triadimenol & - & 1.827 & - & - \\
\hline Trifloxystrobin & - & - & 0.504 & - \\
\hline
\end{tabular}


Table 2. The quantifier ions, qualifier transitions and collision energies for the GC-MS/MS amenable pesticides included in the test materials.

\begin{tabular}{|c|c|c|c|c|c|c|}
\hline GC-MS/MS & $\begin{array}{l}\text { Precursor } \\
\text { ion-1 }\end{array}$ & $\begin{array}{l}\text { Product } \\
\text { ion-1 }\end{array}$ & $\begin{array}{l}\text { Collision } \\
\text { Energy } 1 \\
\text { (V) }\end{array}$ & $\begin{array}{l}\text { Precursor } \\
\text { ion-2 }\end{array}$ & $\begin{array}{l}\text { Product } \\
\text { ion-2 }\end{array}$ & $\begin{array}{l}\text { Collision } \\
\text { Energy } 2 \\
\text { (V) }\end{array}$ \\
\hline Azoxystrobin & 344 & 329 & 15 & 388 & 345 & 15 \\
\hline Bifenthrin & 181 & 166 & 10 & 165 & 115 & 20 \\
\hline Boscalid & 342 & 140 & 15 & 167 & 139 & 20 \\
\hline Carboxin & 235 & 143 & 5 & 143 & 87 & 5 \\
\hline Chlorpropham & 213 & 127 & 15 & 213 & 171 & 5 \\
\hline Chlorpyrifos & 197 & 169 & 10 & 314 & 258 & 12 \\
\hline Chlorpyrifos-methyl & 286 & 93 & 20 & 125 & 79 & 5 \\
\hline Cypermethrin & 163 & 127 & 10 & 181 & 152 & 20 \\
\hline Cyproconazole & 222 & 125 & 15 & 139 & 111 & 15 \\
\hline Cyprodinil & 226 & 225 & 15 & 223 & 208 & 15 \\
\hline Deltamethrin-cis & 181 & 152 & 10 & 253 & 174 & 10 \\
\hline Epoxiconazole & 192 & 138 & 10 & 206 & 165 & 5 \\
\hline Fenbuconazole & 198 & 129 & 10 & 129 & 102 & 15 \\
\hline Fenpropidin & 98 & 70 & 10 & 99 & 71 & 10 \\
\hline Fenpropimorph & 303 & 128 & 5 & 117 & 115 & 10 \\
\hline Fenvalerate & 167 & 125 & 10 & 125 & 99 & 10 \\
\hline Iprodione & 314 & 245 & 10 & 216 & 187 & 5 \\
\hline Isoprothiolane & 290 & 118 & 10 & 290 & 204 & 2 \\
\hline Kresoxim-methyl & 206 & 116 & 4 & 206 & 131 & 10 \\
\hline Lambda-cyhalothrin & 197 & 141 & 10 & 208 & 181 & 10 \\
\hline Malathion & 173 & 99 & 10 & 173 & 127 & 5 \\
\hline Metconazole & 125 & 89 & 10 & 127 & 89 & 10 \\
\hline Pendimethalin & 281 & 252 & 5 & 252 & 162 & 5 \\
\hline Pirimicarb & 238 & 166 & 10 & 166 & 96 & 10 \\
\hline Pirimiphos-methyl & 305 & 290 & 10 & 290 & 233 & 10 \\
\hline Propiconazole & 173 & 145 & 15 & 259 & 173 & 15 \\
\hline Tebuconazole & 250 & 125 & 15 & 125 & 89 & 10 \\
\hline Triadimenol & 168 & 70 & 5 & 128 & 100 & 10 \\
\hline Trifloxystrobin & 222 & 190 & 5 & 186 & 145 & 10 \\
\hline
\end{tabular}


Table 3. The quantifier ions, qualifier transitions and collision energies for the LC-MS/MS amenable pesticides included in the test materials.

\begin{tabular}{lllllll}
\hline LC-MS/MS ESI+ & $\begin{array}{l}\text { Precursor } \\
\text { ion-1 }\end{array}$ & $\begin{array}{l}\text { Product } \\
\text { ion-1 }\end{array}$ & $\begin{array}{l}\text { Collision } \\
\text { Energy } \\
\text { (V) }\end{array}$ & $\begin{array}{l}\text { Precursor } \\
\text { ion-2 }\end{array}$ & $\begin{array}{l}\text { Product } \\
\text { ion-2 }\end{array}$ & $\begin{array}{l}\text { Collision } \\
\text { Energy 2 } \\
\text { (V) }\end{array}$ \\
\hline Boscalid & 343.1 & 307 & 20 & 343.1 & 140 & 25 \\
Carbendazim & 192 & 160 & 20 & 192 & 30 & 29 \\
Cyprodinil & 226 & 93 & 33 & 226 & 77 & 40 \\
Epoxiconazol & 330.11 & 121 & 23 & 330.11 & 91 & 41 \\
Fludioxanil & 247 & 180 & 27 & 247 & 126 & 33 \\
Flusilazole & 316.17 & 247 & 17 & 316.17 & 165 & 20 \\
Isoprothiolane & 291 & 231 & 10 & 291 & 189 & 21 \\
Kresoxim-methyl & 314 & 116 & 30 & 314 & 131 & 20 \\
Pendimethalin & 282.12 & 212 & 10 & 282.12 & 194 & 10 \\
Pirimicarb & 239 & 72 & 16 & 239 & 182 & 14 \\
Pirimiphos-methyl & 306 & 164 & 20 & 306 & 108 & 20 \\
Prothioconazole_desthio & 312 & 70 & 35 & 314 & 127 & 35 \\
Pyraclostrobin & 388.15 & 194 & 11 & 388.15 & 163 & 25 \\
Spiroxamin & 298.26 & 144 & 20 & 298.26 & 100 & 30 \\
\hline
\end{tabular}

